\title{
Computer simulation of the entrepreneurial conduction in virtual e-business clusters
}

\author{
Zheng Y $e^{1 *}$ and Le Jiang ${ }^{2}$
}

\begin{abstract}
The development of virtual e-business cluster is an effective way to cultivate new industries and realize the transformation and upgrading of traditional industries. Based on computer simulation, in this paper, the conduction of entrepreneurial behavior of enterprises in the virtual e-business cluster on their network is studied, and simulation on conductive process and effect is conducted. The research finds that for the two business models of virtual e-business cluster C2C and B2B, if the number of start-ups in the virtual e-business cluster is increased, the business start-ups in the virtual e-business cluster will achieve stable results earlier; and the conduction effect of virtual e-business cluster is more balanced and obvious in the passive impact mode. For B2B, with the impact mode changing from active to passive, entrepreneurial behavior tends to be more balanced from centralization, and the process of entrepreneurial conduction is significantly accelerated, and the conduction reaches the stabilizing effect earlier.
\end{abstract}

Keywords: Computer simulation, E-business entrepreneurship, Virtual cluster, Conduction

\section{Introduction}

Since 2016, China has sped up the supply-side reform and promoted the transformation and upgrading of traditional enterprises through the "Internet plus." The ebusiness industry is developing rapidly. From a practical perspective, more and more traditional industrial clusters cooperate with Alibaba and other Internet leading enterprises to carry out training of transformation and upgrading by e-business, build e-business service system, and strive to build virtual e-business clusters. In 2016, the initial estimate of tax contribution generated by Alibaba group and the Ant Financial Gruop's upstream production and wholesale increments and logistics increments increased by over 200 billion yuan. The development of virtual agglomeration has promoted the vertical division of labor between upstream and downstream professional sectors, as well as the horizontal division between the professional departments in the production chain, thereby increasing the roundabout degree of production and the degree of professional diversification. It can be seen that the development of the virtual cluster of e-business may be an effective way to cultivate new industries and to realize the transformation and

\footnotetext{
* Correspondence: yezheng@zucc.edu.cn

${ }^{1}$ Business School, Zhejiang University City College, Hangzhou, China Full list of author information is available at the end of the article
}

upgrading of traditional industries. Different from the local fission in the traditional cluster entrepreneurship conduction and the expansion of the relationship between the upstream and downstream of the industrial chain, in fact, the virtual industry cluster of e-business is no longer binding on the association of upstream and downstream enterprises in a single industry, but the ebusiness enterprise itself and the organic integration of all kinds of manufacturing, supporting, and service enterprises around its business on the Internet platform. David [1] pointed out that the loose network relationships of open innovation and structures in the cluster provide a new activity environment for innovation, and dynamic multiple network relationships make innovation and imitation easier to happen. Thor and Sylvie [2] believed that cluster networks have promoted innovation and imitation, even a new enterprise. Therefore, the formation and development of virtual e-business industry cluster is closely related to the particularity of the conduction of entrepreneurship.

\section{Research design}

2.1 The entrepreneurial characteristics of virtual e-business cluster

It is proposed by James and Terry [3] that the evolution process of suppliers, distributors, service providers, and 
customers relying on "Internet collaboration technology" as the main form of cooperation and competition is often defined as "e-business communities." The virtual agglomeration of e-business is based on information and communication technology, which takes the enterprises and specific areas in the network as the "core" of competitive advantage, and is integrated across geographical space through implicit or explicit contracts [4]. Under the background of continuous deepening of specialization, the roundabout degree of industrial chain is increasing. All links of production can be carried out in a more wide geographical range in a more decentralized way [5]. Specific geographical areas have been unable to provide all the elements needed for industrial development. With the further development of the enterprise, the demand is gradually shifted from the tangible product to the service products. In the virtual agglomeration of e-business, enterprises can use their core competitiveness to integrate external resources and reduce search cost by relying on information network combined with all forces, so as to achieve optimal allocation of factors in the whole society [6]. The comparison on the entrepreneurial characteristics of virtual e-business clusters and traditional industrial clusters is showed in Table 1.

\subsection{The entrepreneurial network of virtual e-business cluster} The two models in complex networks, the ER model and the BA model, are the most common types. The ER model, as a completely random network, is developed by Erdos and so on. It has two important characteristics that degree distribution tends to average and the connection between nodes appears probabilistic connection. The BA model, which is proposed by Barabasi and so on, is a scale-free network model. It has two important characteristics: the network scale is constantly expanding (growth characteristics) and the new nodes are more likely to connect with the "big" nodes with high connectivity (preferential connection characteristics).

Based on the complex network theory, Powell and other scholars [7] regarded the inter-firm relationship as a network and studied the impact of the structure of the enterprise network and the location of the enterprise in the network on the variables such as the business performance and market structure. Ning Cai and others [8] thought that the enterprise network of industrial cluster is composed of nodes in the network (representing the enterprises in the cluster) and the network sides (representing the relationship between enterprises).

\subsection{Characteristics of entrepreneurship network in the virtual e-business cluster}

Zheng Ye [9] and others believe that the interaction between the industry cluster enterprises plays a key role in the conductive process of entrepreneurial behavior. The decision of the entrepreneurial behavior of a cluster enterprise not only depends on the choice of the neighbor but also is influenced by the complex topology configuration of the cluster enterprise network. The choice of entrepreneurial behavior of cluster enterprises is influenced by external factors, such as market opportunity and other external factors, and the external network of cluster. According to the previous article, the formation of the virtual cluster entrepreneurship network of Alibaba and other e-business enterprises cannot be separated from the conduction of entrepreneurial behavior on the network. Therefore, the conduction of virtual ebusiness cluster is in line with the characteristics of complex social network diffusion. In fact, it is the spread and diffusion of entrepreneurial behavior in the complex network of virtual e-business cluster network.

In this paper, the two types of business models of business to business (B2B) and customer to consumer (C2C) in the virtual cluster of e-business in Alibaba Group are mainly analyzed. B2B refers to the electronic business established by merchants and merchants and is the main business of the Alibaba group. B2B shows the labor division and cooperation between upstream and downstream businesses, centered on large enterprises, and many small and medium-sized enterprises as the periphery, specializing in specialized processing for "core businesses" or providing specialized products according to needs. This type of cluster has a high degree of structure, strong interdependence,

Table 1 Comparison on the entrepreneurial characteristics of virtual e-business clusters and traditional industrial clusters

\begin{tabular}{|c|c|c|}
\hline & Entrepreneurial characteristics of traditional industrial clusters & Entrepreneurial characteristics of virtual e-business clusters \\
\hline $\begin{array}{l}\text { Entrepreneurial } \\
\text { agglomeration }\end{array}$ & $\begin{array}{l}\text { Geographical proximity, strong localization, } \\
\text { industrial chain platform }\end{array}$ & Organized closely, cross regional, Internet platforms \\
\hline Motive force & Driven by factors and specialization & Driven by Internet innovation \\
\hline Entrepreneurial approach & Face-to-face communication & Virtual networking and electronization \\
\hline Network characteristics & $\begin{array}{l}\text { Regional network formed by specialized division } \\
\text { of work and cooperation }\end{array}$ & $\begin{array}{l}\text { Open and loose type work and cooperation network } \\
\text { based on the Internet }\end{array}$ \\
\hline Form of competition & $\begin{array}{l}\text { "Exclusive" competition in the decision of } \\
\text { information regionalism }\end{array}$ & $\begin{array}{l}\text { Open "inferiority" competition determined by } \\
\text { network technology and market economy law }\end{array}$ \\
\hline Mode of payment & Traditional payment mode & Internet payment \\
\hline
\end{tabular}


and low homogeneity in the group. It shows that there are a small number of nodes with relatively high degree in the internal network structure. Moreover, the big enterprise is the center, that is, the "big" nodes with higher connectivity exist in the BA model. The high degree of structure in the network indicates that the relationship between enterprises is generated by the priority connection of large enterprises, that is, the priority connection characteristics do exist in the $\mathrm{BA}$ model. $\mathrm{C} 2 \mathrm{C}$ is the e-business between individuals and individuals. The typical representative is virtual ebusiness cluster platform of Taobao in Alibaba group. C2C is based on equal market trading, and the whole virtual cluster is completed by the various subjects with the level of connection. This type of cluster is relatively low in structure, high in homogeneity among clusters, and not very strong on bilateral dependence. It shows that the similarity between the subjects is high and the importance is converging, and the main way is the horizontal connection, that is, the degree distribution of nodes in the ER model is relative average. The low degree of structure indicates that the degree of interlocking and dependency is weak, and the relationship between subjects is not affected by the original relationship. That is to say, in the ER model, the edges of the nodes are connected with the same probability. On these grounds, the connection probability of the two virtual cluster network models of $\mathrm{C} 2 \mathrm{C}$ and B2B can be obtained according to Table 2.

\subsection{The process of entrepreneurship conduction of virtual e-business cluster}

The innovative behavior of some subjects in the virtual cluster of electronic business directly contributes to the innovative behavior of the subjects associated with it, and is the diffusion of the entrepreneurial behavior among the subjects. Therefore, based on the network relationship, the conduction of enterprises in the virtual e-business cluster is that the entrepreneur and decision-making process of the subject is vulnerable to the impact of the subject selection, which is in line with the neighborhood effect of complex network innovation diffusion. Zhenglong Zhao [10] believes that in the neighborhood effect, the mode of impact among individuals is the two modes of active and passive effects. The mode of active impact in virtual ebusiness cluster refers to a conscious self-publicity, so as to facilitate the neighborhood entrepreneurship to enhance cooperation, especially to the key neighbors. The mode of passive impact means the goal individuals do not take any conscious actions to impact the diffusion of innovation, and the probability of diffusion depends on the rational decision-making process of the neighbors. Based on the availability of research data, the intensity of the connections among individuals in the network is neglected in this paper. Then, the probability of the two modes of entrepreneurship conduction in virtual e-business clusters is as shown in Table 3.

Research on the platforms in virtual e-business cluster shows that in some clusters, entrepreneurial behavior can better promote the entrepreneurship in the virtual ebusiness cluster, while others are unable to form an effective diffusion or spread, and the impact of the virtual ebusiness cluster is very limited. Therefore, not only the neighborhood effect impacts the entrepreneurial behavior of the subjects in the virtual e-business cluster but also the complex topology configurations of $\mathrm{C} 2 \mathrm{C}$ and $\mathrm{B} 2 \mathrm{~B}$ also have an impact on the process and effect of entrepreneurial conduction. In this paper, the conduction amplification factor $\mathrm{E}$ and the conduction concentration $\mathrm{CV}$ are used to reflect the cumulative number of entrepreneurial activities and the centralization trend of entrepreneurial behavior.

$$
\mathrm{CV}=\frac{\sqrt{\frac{\sum_{i-1}^{m}\left(E_{i}-A E_{m}\right)^{2}}{m}}}{A E_{m}}
$$

$$
A E_{m}=\frac{\sum_{i-1}^{m} E_{i}}{m}
$$

$A E_{m}$ means the average number of entrepreneurial times of all the enterprises in a virtual e-business cluster; $m$ means the number of enterprises in the cluster; and $E_{i}$ means the number of entrepreneurial times of the enterprise $\mathrm{i}$ in the cluster.

\section{Methodology \\ 3.1 Multi-agent simulation}

Using the multi-agent simulation model, Rosanna [11] researched the complex adaptive systems such as cluster innovation network and new product development system in which the network plays the key role, and he believed the multi-agent simulation model is very suitable

Table 2 Probability of two types of complex network model

\begin{tabular}{lll}
\hline & Connection probability & Description \\
\hline ER model & $\prod_{i}=\frac{1}{N(t)}$ & $\begin{array}{l}\Pi_{i} \text { represents the probability of connection between node } i \text { and new nodes; } N(t) \text { represents the number of } \\
\text { nodes at the time of t; } k_{i} \text { represents the degree of node } i ; j=1 \sim N \text { in } \sum_{j} k_{j}(N \text { is the number of existing nodes) }\end{array}$ \\
& indicates that the degree of all nodes is added to the total.
\end{tabular}


Table 3 The conduction probability of entrepreneurship between individuals

\begin{tabular}{lll}
\hline & Conduction probability & Description \\
\hline Active impact & $D_{i} \rightarrow j=\frac{1}{k_{i}}$ & $\begin{array}{l}\text { Where, } D_{i} \rightarrow j=\text { the probability of conducting from node } i \text { to node } j ; \\
\text { Passive impact }\end{array}$ \\
\hline
\end{tabular}

for the study of various phenomena appearing in the industrial cluster. The entrepreneurial behavior of enterprises in the virtual e-business cluster is conducted through the information flow sharing, knowledge transfer and learning, diversified behavior characteristics, innovation ability, and the complex relationship and evolution of individual behavior in the network. Therefore, the effects of "initial conditions" and "path dependence" on entrepreneurial conduction can be investigated by using the simulation method. MATLAB7.5 is used in this paper to simulate the research model. ${ }^{1}$ First, the model of network for virtual e-business cluster is generated, and then the conduction simulation of entrepreneurial behavior is carried out.

\subsection{Network model}

In the generation of network models, starting with an initial node, a new node is added each time according to the rules of the connection probability of the two types of nodes (Table 2), all the way up to 100 nodes, and the network diagram and node degree distribution diagram (as shown in Fig. 1) and the number of network nodes and indexes of network edge under two models are output: The $\mathrm{C} 2 \mathrm{C}$ network model contains 100 nodes, 101 edges, and the average degree distribution (between 0 and 10). The B2B network model contains 100 nodes and 187 sides, and "big" nodes with high connectivity (the general node degree is between 0 and 30 ).

\section{a}

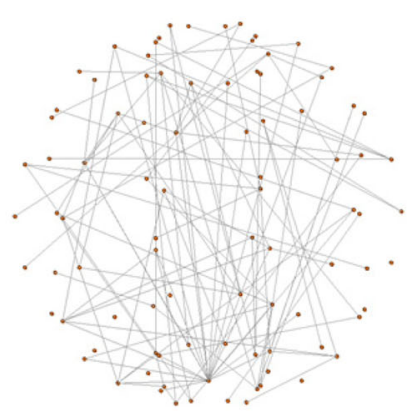

Network diagram of C2C model

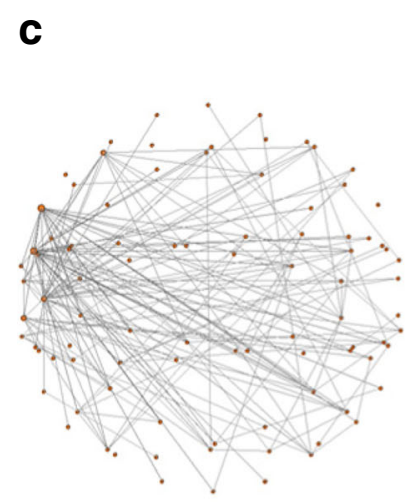

Network diagram of B2B model b

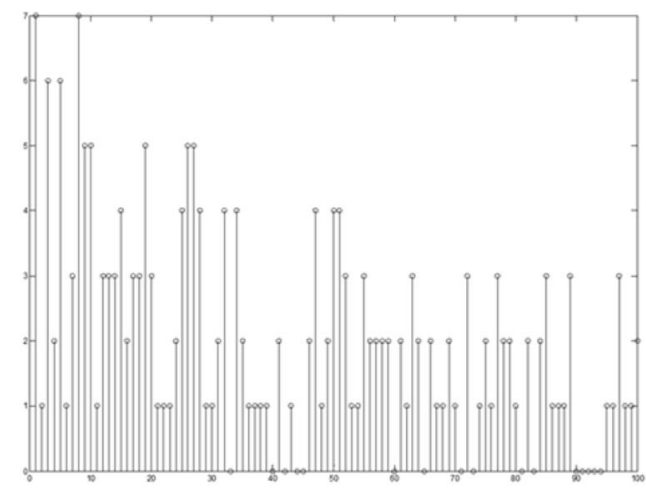

Node degree distribution diagram of $\mathrm{C} 2 \mathrm{C}$ model

d

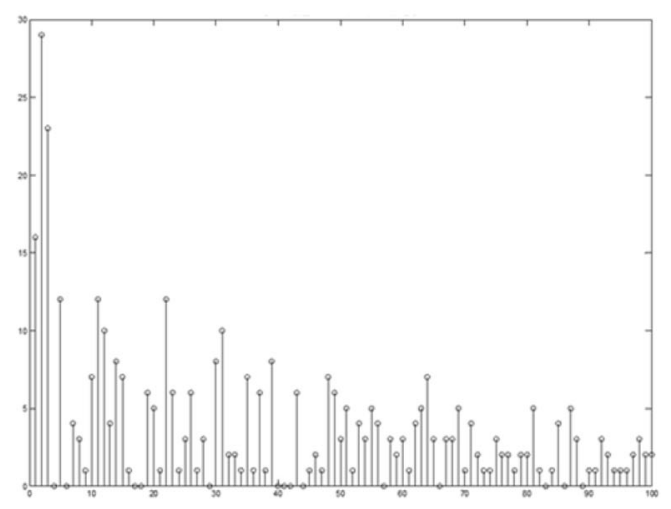

Node degree distribution diagram of B2B model

Fig. 1 Network diagram and node degree distribution diagram of two types of models. a Network diagram of C2C model. b Node degree distribution diagram of C2C model. c Network diagram of B2B model. $\mathbf{d}$ Node degree distribution diagram of B2B model 


\subsection{Simulation of entrepreneurial conduction}

Under the two types of network models, the initial entrepreneurial enterprises (target nodes) in the virtual cluster of e-business are selected randomly. The number of initial target nodes is set to 1 and $10 \%$ of the initial nodes, respectively. According to the conduction probability D (Table 3), the target node carries out an entrepreneurial conduction to the neighbor nodes. The conducted neighbor node is the target node at the beginning of the next conductive process, and the conduction can be repeated and accumulated. The conductive process diagram (Fig. 2), the conduction effect diagram (Fig. 3) after 25 times of conduction, and the node diagram of two kinds of model after entrepreneurship conduction (Fig. 4) are worked out, and the conduction amplification factor $\mathrm{E}$ and the $\mathrm{CV}$ index of the entrepreneurial concentration degree are output. According to the conductive process diagram of the simulation output, the difference of conduction time $\mathrm{T}$ (the number of times when conduction tends to be stable) is analyzed so as to compare the entrepreneurial conduction time under different network structure and network relationship.

\section{Results and discussion}

Through multiple simulation after adjustment of model parameters, it is found that for $\mathrm{C} 2 \mathrm{C}$ and $\mathrm{B} 2 \mathrm{~B}$, the changes in the number of conduction times have no substantial impact on $\mathrm{T}$ and $\mathrm{CV}$ in addition to the change in $\mathrm{E}$ with almost the same proportion (cumulative number of entrepreneurial times) while other parameters remain the same. It may be considered that the number of conduction does not affect the heterogeneity of the conduction results. Therefore, in this paper, the simulation results under different parameters with 25 conduction times are given, and the change on the two kinds of parameters (the number of initial target node and the mode of impact) and the impact of the simulation model are mainly analyzed.

\subsection{Influence of the number of initial target nodes on the result of entrepreneurial conduction}

After changing the number of initial target nodes, the difference between the conductive process of the two models after 25 conduction times in different impact modes is shown in Fig. 2. Compared with the active impact mode, the number of initial target node increased from 1 to $10 \%$. The conduction time $\mathrm{T}$ of the $\mathrm{C} 2 \mathrm{C}$ model was reduced from 8 to 4 , and the conduction time $\mathrm{T}$ of the $\mathrm{B} 2 \mathrm{~B}$ model was reduced from 7 to 4 . Compared with the passive impact mode, the number of initial target node increased from 1 to $10 \%$. The conduction time $\mathrm{T}$ of the $\mathrm{C} 2 \mathrm{C}$ model was reduced from 10 to 4 , and the conduction time $\mathrm{T}$ of the $\mathrm{B} 2 \mathrm{~B}$ model decreased from 8 to 3 . It can be seen that for the two types of model, increasing the number of initial target nodes makes the conduction reach a stable effect earlier.

\subsection{Influence of impact mode on the result of entrepreneurial conduction}

After changing the impact mode among nodes, the difference between the conductive effect of the two models after 25 conduction times under different number of initial target nodes is shown in Fig. 3. It is found by comparison on two types of model transforming from active impact to passive impact when the number of initial target node is $1 \%$ and two types of model transforming from active impact to passive impact when the number of initial target node is $10 \%$, the cumulative number of entrepreneurship in different enterprises of the $\mathrm{C} 2 \mathrm{C}$ model and the $\mathrm{B} 2 \mathrm{~B}$ model are more balanced in the passive impact mode. In particular, under the $\mathrm{C} 2 \mathrm{C}$ model, the cumulative number of entrepreneurship is extremely uneven in the

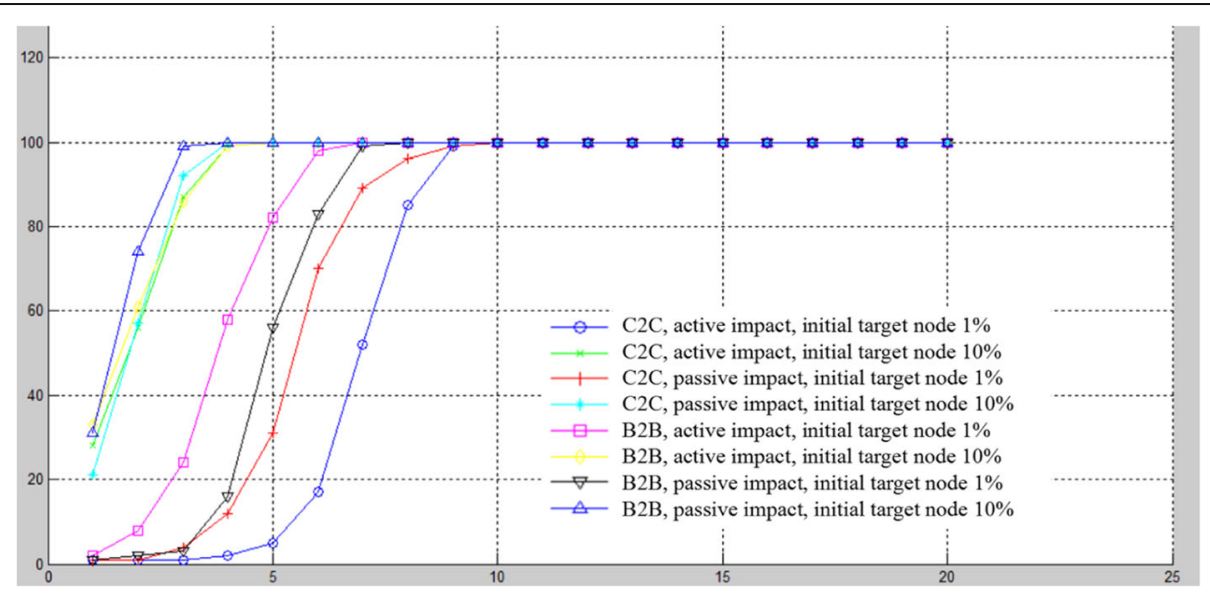

Fig. 2 Conductive process diagram 


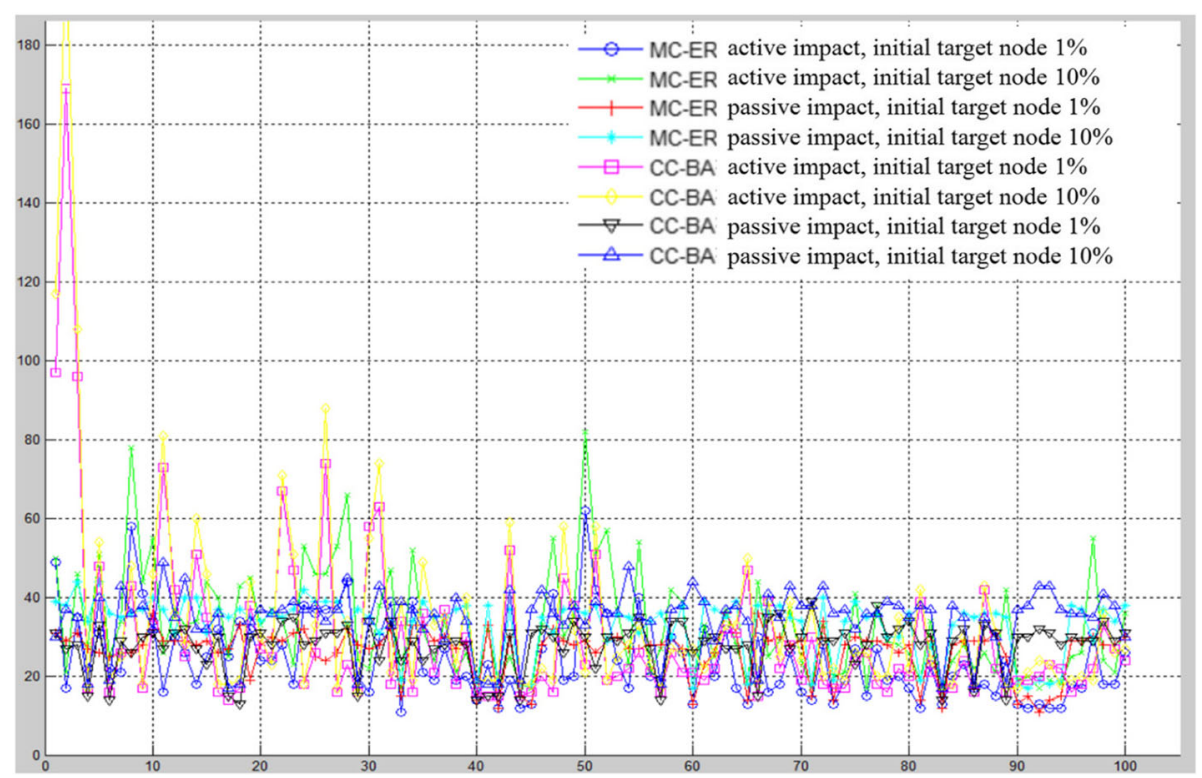

Fig. 3 The impact of input parameter difference on the effect of entrepreneurship conduction

active impact mode, while it is well-balanced in the passive impact mode. From the index values (Table 4), for the two models of $\mathrm{C} 2 \mathrm{C}$ and $\mathrm{B} 2 \mathrm{~B}$, the conduction effect of enterprises in the virtual e-business cluster in the passive impact mode is better than that of the active impact mode.

\section{Conclusions}

Based on the simulation results, in this paper, some suggestions on the entrepreneurship policy of virtual cluster of e-business are proposed as follows: First, for the virtual e-business cluster, a good environment shall be created for network innovation and entrepreneurship to stimulate business start-ups and increase the number of start-ups, which is conducive to accelerating and promoting the entrepreneurship and conductive process of virtual e-business clusters and increasing the limit number of start-ups. Second, for virtual e-business clusters with a certain scale, there is a limit to the conduction of entrepreneurial behavior among enterprises, which is in line with what has been observed in practice. Not all enterprises can always adopt an innovative development strategy in their development. There are always some enterprises Will decline or gradually withdraw from the market. Therefore, the growth and development of virtual e-business cluster has a certain threshold. Thirdly, more attention should be paid to the passive impact mode in the cooperative relations between enterprises when promoting the conduction of entrepreneurial behavior of enterprises in virtual e-business cluster. That is to say, while encouraging and guiding the start-up enterprises to find suitable e-business related enterprises for

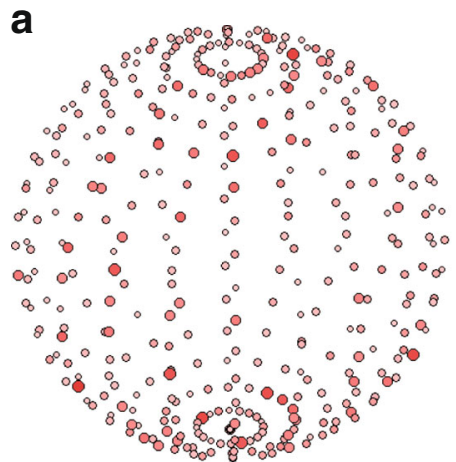

C2C model b

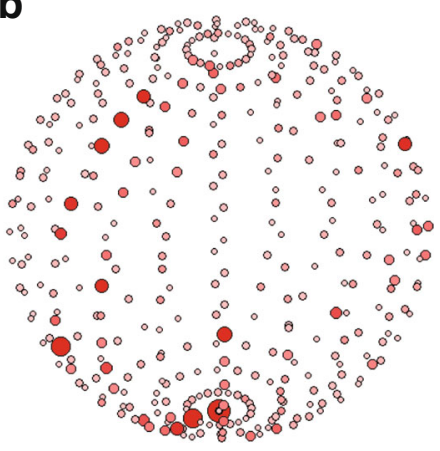

B2B model

Fig. 4 The node diagram of the two types of model after the entrepreneurship conduction. a C2C model. $\mathbf{b}$ B2B model 
Table 4 Output index value of different input parameters

\begin{tabular}{|c|c|c|c|c|c|c|c|c|}
\hline \multirow[t]{3}{*}{ Model } & \multicolumn{4}{|c|}{ Initial target node $10 \%$} & \multicolumn{4}{|c|}{ Initial target node $1 \%$} \\
\hline & \multicolumn{2}{|l|}{$\overline{C V}$} & \multicolumn{2}{|l|}{ E } & \multicolumn{2}{|l|}{$\mathrm{CV}$} & \multicolumn{2}{|l|}{$E$} \\
\hline & Active impact & Passive impact & Active impact & Passive impact & Active impact & Passive impact & Active impact & Passive impact \\
\hline $\mathrm{C} 2 \mathrm{C}$ & 0.4161 & 0.2023 & 5344 & 8262 & 0.5866 & 0.3114 & 1002 & 2447 \\
\hline B2B & 0.7146 & 0.2839 & 6073 & 8998 & 0.8993 & 0.3316 & 1974 & 3629 \\
\hline
\end{tabular}

innovation activities, the entire cluster should be promoted to enhance the ability of enterprises to formulate their plans and strategies for the development of ebusiness so as to encourage more e-business affiliates to remain focused on cooperative innovation activities and to follow the long-term development perspective.

\section{Endnotes}

${ }^{1}$ The generation of network models and simulations is based on Monte Carlo method. Based on the distributed pseudo random number generated by Mersenne Twister, the network and simulation are generated according to the corresponding probabilistic models.

\section{Abbreviations}

B2B: Business to business; C2C: Customer to consumer

\section{Acknowledgements}

The authors would like to thank Mr. John Schaffhausen, Walden University, USA, for the help of our research.

\section{Funding}

The authors acknowledge the National Natural Science Foundation of China (Grant: 71603235), Humanities and Social Sciences Research Program Youth Fund of Education Department of China (Grant: 16YJC630157), and Hangzhou Social Sciences Fund for Distinguished Young Scholars (Grant: 2016RCZX32).

\section{Authors' contributions}

$Z Y$ is the main writer of this paper. She proposed the main idea, completed the simulation, and analyzed the result. $\downarrow J$ wrote the simulation code and gave some important suggestions for the computer simulation result. Both authors read and approved the final manuscript.

\section{Competing interests}

The authors declare that they have no competing interests.

\section{Publisher's Note}

Springer Nature remains neutral with regard to jurisdictional claims in published maps and institutional affiliations.

\section{Author details}

${ }^{1}$ Business School, Zhejiang University City College, Hangzhou, China. ${ }^{2}$ Haige Hightone Communications Co., LTD, Hangzhou, China.

Received: 9 February 2018 Accepted: 18 April 2018

Published online: 27 April 2018

\section{References}

1. D Tamoschus, Geographies of open source biotechnology innovation: buzz, pipelines, and proximity in a virtual cluster. Int. J. Knowl-Based Organ. 2(2), 21-39 (2012)

2. T Sigfusson, S Chetty, Building international entrepreneurial virtual networks in cyberspace. J. World Bus. 48(2), 260-270 (2013)

3. A James, W Terry, Factors influencing growth potential of e-commerce in emerging economies: an institution based on framework and research propositions. Thunderbird Int. Bus. Rev. 57(3), 197-215 (2015)
4. M Abebe, Electronic commerce adoption, entrepreneurial orientation and small and medium-sized enterprise (SME) performance. J. Small Bus. Enterp. Dev. 21(1), 100-116 (2014)

5. C Avgerou, B Li, Relational and institutional embeddedness of web-enabled entrepreneurial networks: case studies of entrepreneurs in China. Inf. Syst. J. 23(4), 329-350 (2013)

6. CM Chiu, MH Hsu, ETG Wang, Understanding knowledge sharing in virtual communities: an integration of social capital and social cognitive theories. Decis. Support. Syst. 42(3), 1872-1888 (2013)

7. WW Powell, KW Koput, DL Smith, Inter organizational collaboration and the locus of innovation: networks of learning in biotechnology. Adm. Sci. Q. 41(1), 116-145 (1996)

8. N Cai, Ch Huang, Risk and structure evolving of industry cluster: a computer simulation from complex network perspective. J. Chongqing Univ. (social science edition). 18(1), 5-11 (2012) (in Chinese)

9. Z Ye, JZ Zheng, Network characteristics and corporate entrepreneurship of cluster enterprises: an empirical study based on entrepreneurial competence. Sci. Res. Manag. 35(1), 58-65 (2014) (in Chinese)

10. ZL Zhao,Z Chen, L Li, Research on diffusion of innovation based on firm network. J. Shanghai Jiaotong Univ. 42(9), 1534-1540 (2008) (in Chinese)

11. G Rosanna, Use of agent-based modeling in innovation/new product development research. J. Prod. Innov. Manag. 22(5), 380-398 (2005)

\section{Submit your manuscript to a SpringerOpen ${ }^{\circ}$ journal and benefit from:}

- Convenient online submission

- Rigorous peer review

- Open access: articles freely available online

- High visibility within the field

- Retaining the copyright to your article

Submit your next manuscript at $\gg$ springeropen.com 